\title{
Association of Murine Double Minute 2 polymorphisms with gastric cancer: A systematic review with meta-analysis
}

\author{
MAFALDA TIMÓTEO $^{1}$, ANA TAVARES ${ }^{1,2}$, SARA CRUZ $^{1}$,

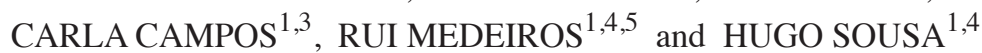 \\ ${ }^{1}$ Molecular Oncology and Viral Pathology Group (CI-IPOP); ${ }^{2}$ Pathology Department; ${ }^{3}$ Microbiology Service; \\ ${ }^{4}$ Virology Service, Portuguese Oncology Institute of Porto, 4200-072 Porto; ${ }^{5}$ Research Department, Portuguese \\ League Against Cancer (Liga Portuguesa Contra o Cancro-Núcleo Regional do Norte), 4200-172 Porto, Portugal
}

Received December 11, 2019; Accepted April 20, 2021

DOI: $10.3892 /$ br.2021.1445

\begin{abstract}
Gastric cancer (GC) is the 5th most common type of cancer, with the 3rd highest mortality rate worldwide in both sexes. Murine double minute 2 (MDM2) protein is the major negative regulator of $\mathrm{p} 53$, and genetic polymorphisms in this gene have shown to be associated with several types of cancer. In the present study, a literature search was performed using PubMed and Scopus with the following key word combinations 'gastric cancer AND polymorphism AND MDM2'. Studies were carefully revised according to the Preferred Reporting Items for Systematic Reviews and Meta-Analyses guidelines to identify eligible studies that matched the inclusion criteria. Statistical analysis was performed to assess the association between the different genetic polymorphisms and GC risk, by calculating the odds ratios (OR) and the confidence intervals (CI), with a $5 \%$ level of significance. A total of 11 manuscripts studied MDM2 polymorphisms in GC: rs937283 (n=1), rs3730485 $(n=1)$ and rs2279744 $(n=9)$. Both the rs937283 and rs3730485 reports showed an association with GC; however, there was only one study on each of these polymorphisms in the literature. A meta-analysis was performed for the rs2279744 polymorphism, of which studies showed a positive association between the $\mathrm{G}$ allele and risk of $\mathrm{GC}$, either in the dominant model $(\mathrm{OR}=1.46 ; 95 \% \mathrm{CI} 1.21-1.75 ; \mathrm{P}<0.001)$ or recessive model (OR 1.65; 95\% CI 1.45-1.87; P<0.001). In conclusion, genetic polymorphisms in MDM2 seemed to be associated with an increased risk of GC development, nevertheless, the number of studies were relatively low and the studied populations were primarily Chinese. The present meta-analysis emphasizes the need for additional studies in other populations to corroborate the association of these polymorphisms with GC.
\end{abstract}

Correspondence to: Professor Hugo Sousa, Molecular Oncology and Viral Pathology Group (CI-IPOP), Portuguese Oncology Institute of Porto, Rua Dr. António Bernardino de Almeida, 6657 Estrada interior da Circunvalação, 4200-072 Porto, Portugal E-mail: hugo.sousa@ipoporto.min-saude.pt

Key words: gastric cancer, murine double minute 2, polymorphism, single nucleotide polymorphism, meta-analysis

\section{Introduction}

Worldwide, gastric cancer (GC) affects over a million individuals and leads to 783,000 deaths each year, being the 5th most common type of cancer and the 3rd major cause of cancer-related deaths, in both sexes (1). Despite the existence of different patterns of acquisition (sporadic, familial or hereditary), the most widely accepted mechanism of gastric carcinogenesis describes the evolution from chronic atrophic gastritis into intestinal metaplasia, dysplasia and finally, the occurrence of sporadic GC $(2,3)$. Other risk factors, such as Helicobacter pylori, a high level of salt intake and genetic polymorphisms in pro- and anti-inflammatory cytokine coding genes, have been considered to have a significant impact, and the interaction between these factors may be crucial for development of cancer (4-6).

TP53 is the most commonly mutated gene in numerous types of cancer; it encodes one of the most important tumor suppressors proteins, p53, which impacts multiple pathways of carcinogenesis, not only due to mutations, but also by the de-regulation of p53 pathways $(7,8)$. The murine double minute 2 (MDM2) gene encodes for $\mathrm{mdm} 2$, an E3 ubiquitin ligase, that acts as the major p53 negative regulator implicated in several types of cancer $(9,10)$. Under physiological conditions, mdm 2 binds to the p53 transactivation domain, leading to the inhibition of its transcriptional activities, followed by the promotion of proteasomal degradation and p53 export from the nucleus, inactivating its functions (11). Some studies have shown that MDM2 amplification occurs in GC, with an expected impact on p53 pathways $(12,13)$. Furthermore, similar to what has been described for other types of cancer (14-19), MDM2 polymorphisms that can lead to differential protein activity may have an impact on GC susceptibility (20-23).

The aim of the present study was to summarize the studies that analyzed $M D M 2$ polymorphisms and their associations with the risk of GC development by performing a systematic review of published manuscripts.

\section{Materials and methods}

Literature search and study selection. A systematic review of the literature was performed using the Preferred Reporting 


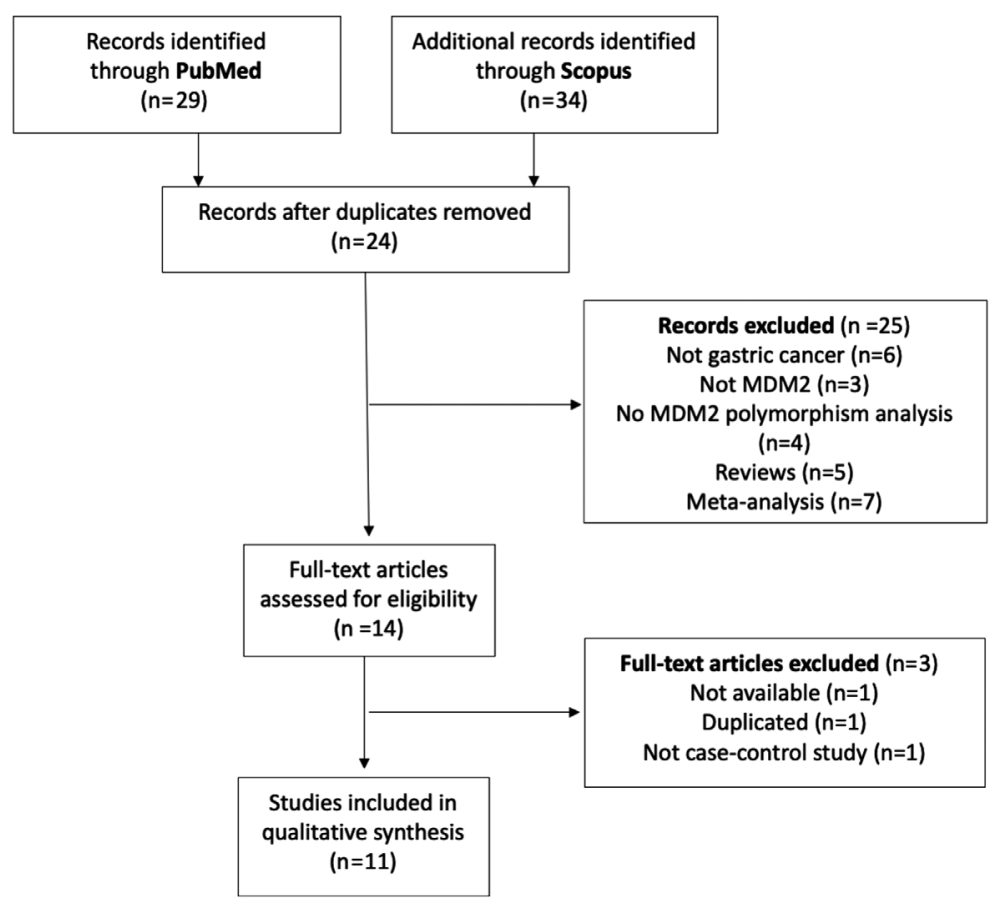

Figure 1. Preferred Reporting Items for Systematic Reviews and Meta-Analyses flowchart for selection of relevant studies.

Items for Systematic Reviews and Meta-Analyses (PRISMA) guidelines (24). The literature search was performed using PubMed and Scopus on 18th October 2019 (and revised on 31st July 2020) using the following key words combination: 'gastric cancer AND polymorphism AND MDM2'. Different combinations of words and MESH terms were tested and the selected query was the most representative. The literature search was performed independently by two of the authors without any restrictions on time, sample size or population studied.

Studies were included if they met the following inclusion criteria: i) Assessment of any MDM2 polymorphism and risk of GC; ii) case-controlled design, and iii) genotype frequencies for both cases and controls were provided. Studies were excluded if i) they were published in any language other than English; ii) duplicated data; iii) they used another study design rather than case-control (reports of clinical cases, comments, series, reviews and editorials); and iv) if insufficient data was provided or the data was not available. Review studies were checked for their references for other relevant studies. Articles which included $\geq 2$ case-control tests or $\geq 2$ single-nucleotide polymorphisms (SNPs) were regarded as two or more different studies. Case-control studies were the only selected type to be included as they provide the necessary data for meta-analysis considering the association with GC risk. The reference lists of the selected studies and prior systematic reviews/meta-analysis was also reviewed and compared with our list of included studies.

Data extraction. According to the PRISMA guidelines, each step was performed independently by two investigators and discrepancies were decided by a third investigator. Briefly, manuscripts were first screened by analyzing titles and abstracts, based on the inclusion/exclusion criteria. Full texts were then reviewed and data extracted (first author, year of publication, original country, the ethnicity of the population studied, genotyping method, histological GC, numbers for cases and controls of all genotypes). All studies were assessed for Hardy-Weinberg equilibrium of genotypes distribution and a qualitative analysis was performed based on the Newcastle-Ottawa Scale (NOS) and considering important information for case-controlled studies (Table SI) (25). All articles with a NOS scale score $\geq 8$ were considered high-quality studies.

Statistical analysis. The collected data were analyzed using Review Manager version 5.3 (The Nordic Cochrane Centre, The Cochrane Collaboration) to assess the association between the different genotypes and GC risk, by calculating the odds ratios $(\mathrm{OR})$ and the confidence intervals $(\mathrm{CI})$ with $\mathrm{P}<0.05$. Funnel and forest plots were created to summarize the differences in the studies and their significance, considering the relative weight of each study, according to the random effects model.

\section{Results}

Characteristics of the included studies. A flow diagram of study selection is presented in Fig. 1. The literature search in PubMed and Scopus provided a total of 63 manuscripts, of which 24 were duplicated between databases. All abstracts from the remaining 39 manuscripts were reviewed, and 25 were excluded for the following reasons: Not GC $(n=6)$, not MDM2 ( $\mathrm{n}=3)$, no $M D M 2$ polymorphism analysis $(\mathrm{n}=4)$, reviews $(n=5)$ and meta-analysis $(n=7)$. A total of 14 manuscripts were assessed for full-review, of which three were excluded: One manuscript was not available, one had a duplicated population of another published study and one was not a case-controlled study. After the revision process, a total of 11 articles were used for data analysis (21,23,26-34). Amongst the included studies, 10 studies were performed in Asian populations and one in a Brazilian population.

Regarding the SNPs studied in association with GC, 1 study analyzed rs937283, 1 analyzed rs3730485 and 9 studies 


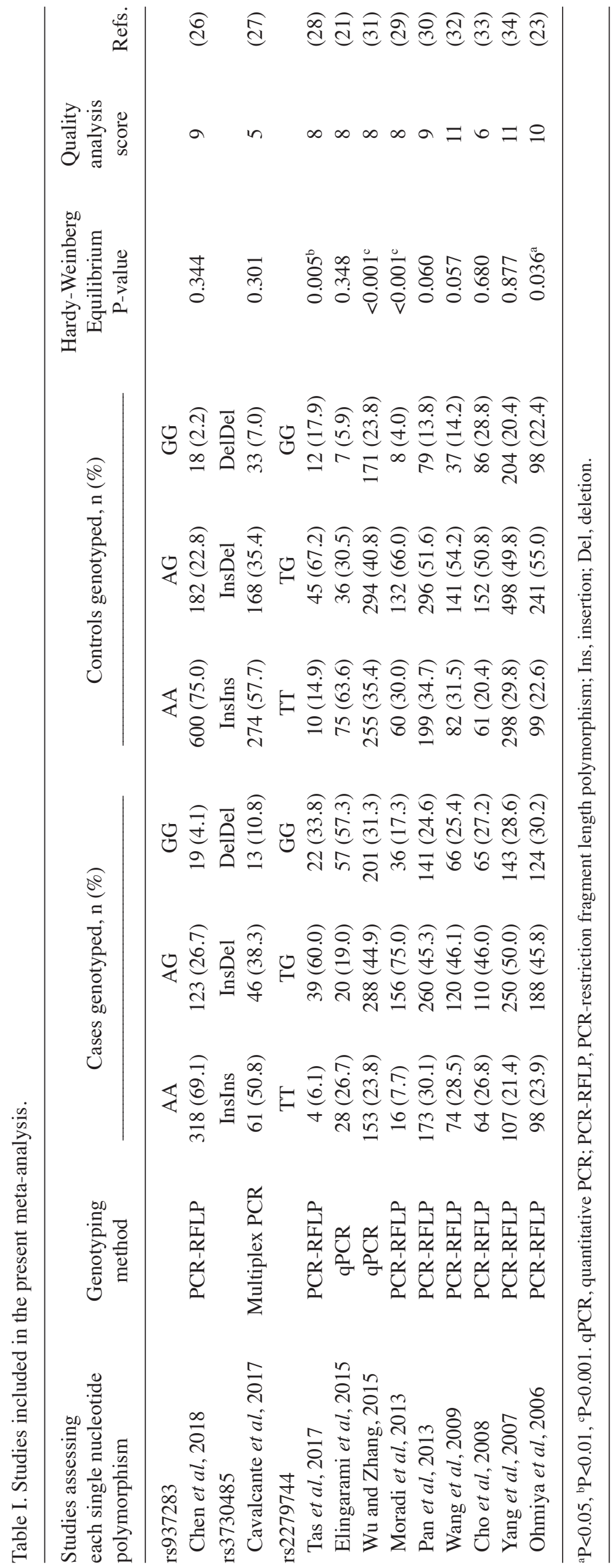




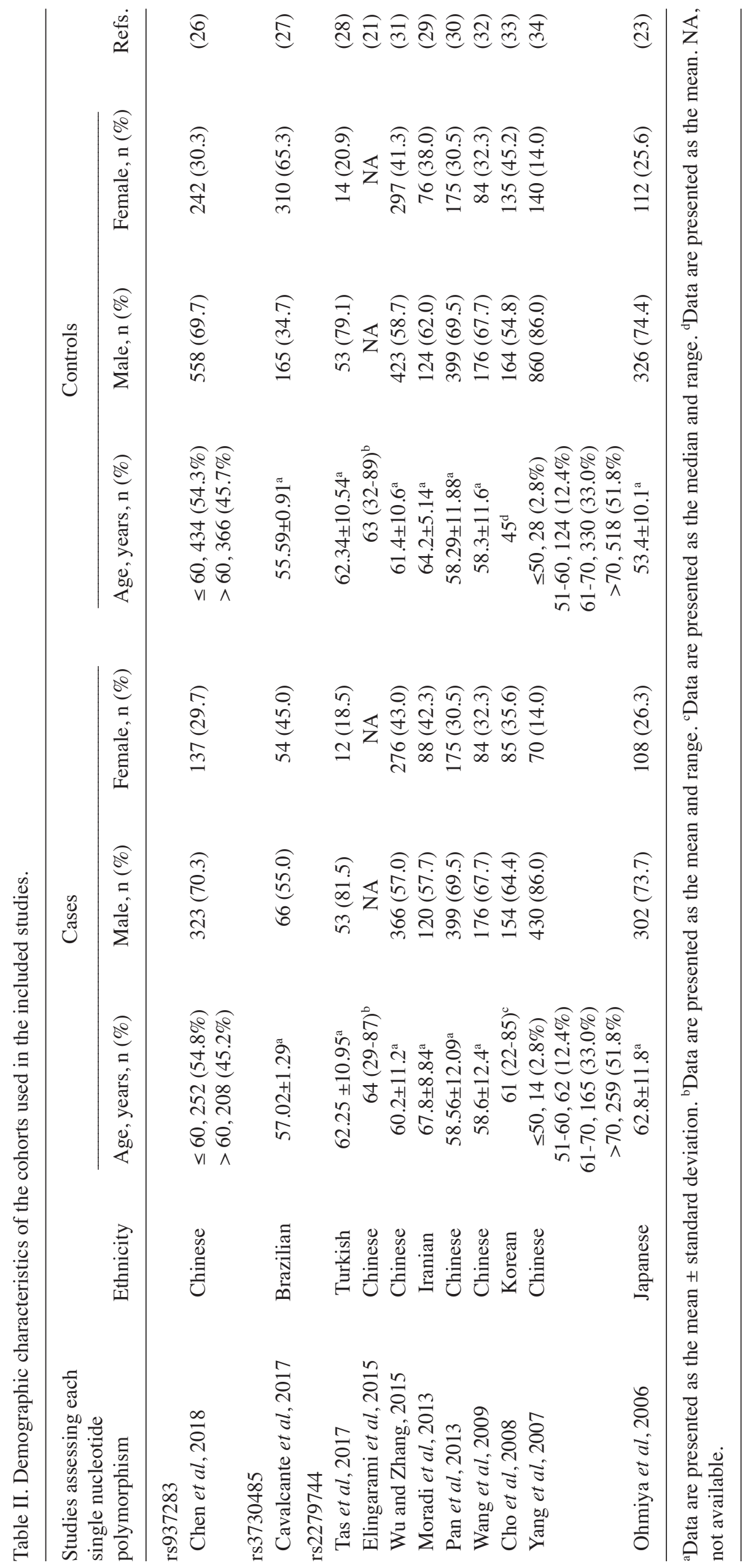



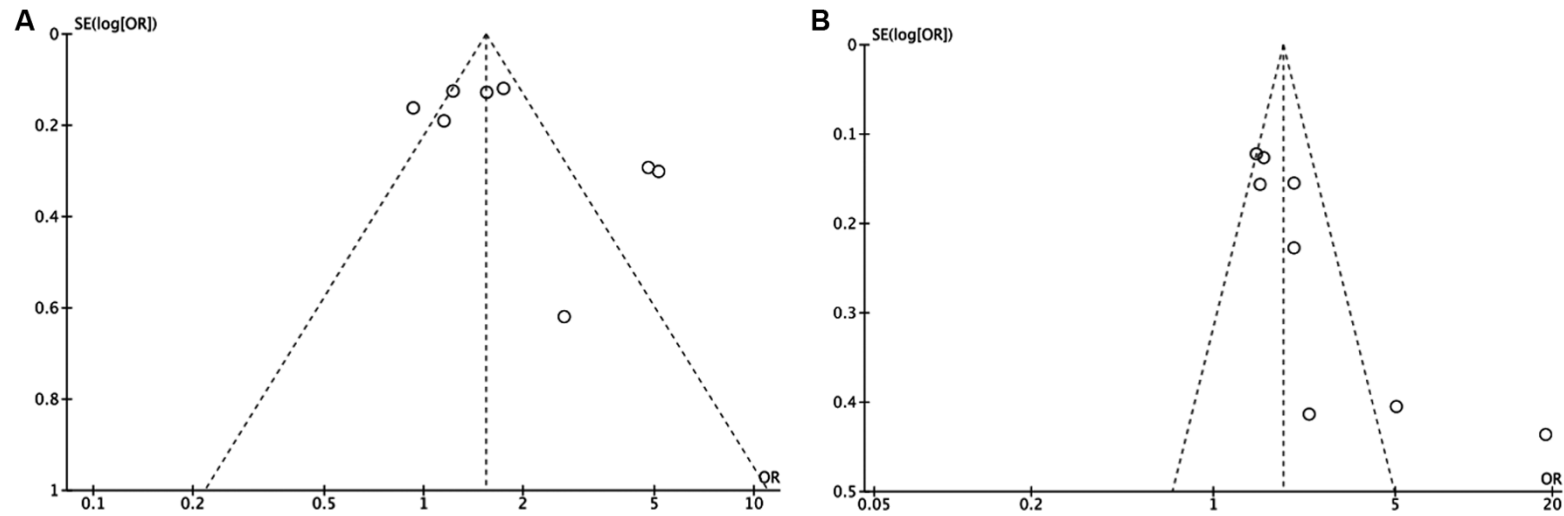

Figure 2. Funnel plots to assess bias of the included studies. Funnel plots of (A) the dominant model and (B) the recessive model. OR, odds ratio; SE, Standard error of the mean.

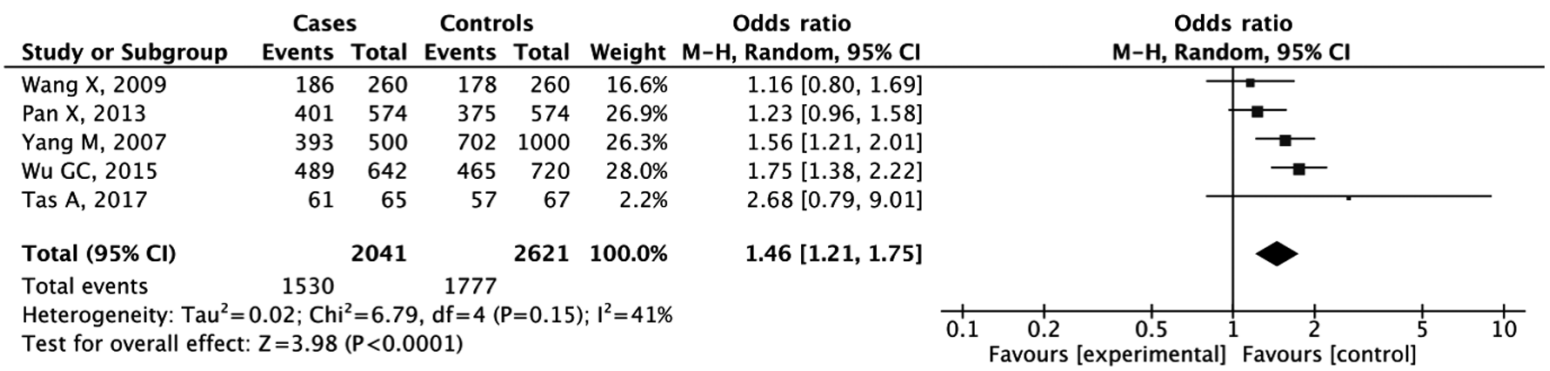

Figure 3. Forest plot for analysis of the dominant model (GG + TG vs. TT). OR, odds ratio; 95\% CI, 95\% confidence interval.

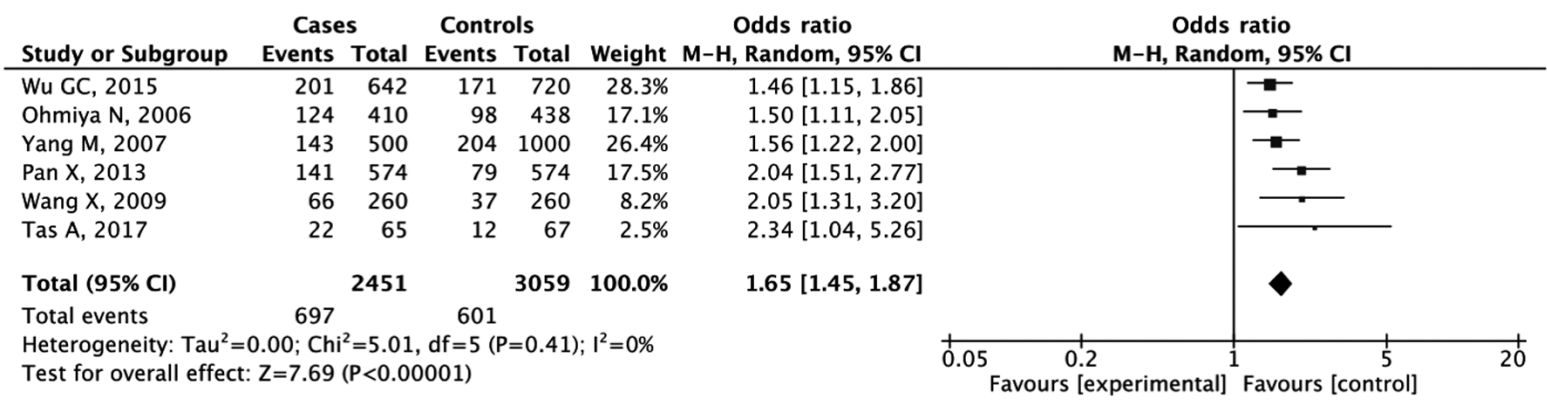

Figure 4. Forest plot for the recessive model (GG vs. TG + TT). OR, odds ratio; 95\% CI, 95\% confidence interval.

analyzed the rs2279744 polymorphism. Both rs937283 and rs3730485 reports showed an association with GC, nevertheless there was only one study of each in the literature, thus no further analysis was performed. Regarding rs2279744, a total of 3,003 cases of GC and 3,676 controls were included in the present meta-analysis. The genotyping information of the included studies is described in Table I and the population demographics of each study are presented in Table II. Amongst rs2279744, the genotype distributions in the controls of 4 studies $(23,28,29,31)$ were not consistent with the HWE $(\mathrm{P}<0.050)$; and regarding the quality analysis, one study was considered of 'low quality' (QA score $<8$; Table I and SII).

Meta-analysis. Of the three SNPs described in the different studies, only rs2279744 was the subject of more than one study with genotyping data. Data analysis was performed considering the $\mathrm{G}$ allele as the risk allele in different genetic models: i) the dominant model (GG + TG vs. TT), and ii) the recessive model (GG vs. TT + TG) (35). Meta-analysis was performed only with studies with a QA score $\geq 8$. In the funnel plot analysis, three studies deviated from the expected outcomes either in the dominant or recessive model analysis $(\mathrm{P}<0.05$; Fig. 2$)$. The studies which showed deviation from the expected outcomes, according to both genetic models, were Elingarami et al (21) and Moradi et al (29), as well as also Ohmiya et al (23) in the dominant model, which may indicate publication bias. For this reason, they were eliminated from the respective genetic model of the meta-analysis.

As shown in the forest plots (Figs. 3 and 4), the results of analysis of the dominant model showed that GG + GT were significantly associated with increased GC risk compared with the TT genotype (OR, 1.46; 95\% CI, 1.21-1.75; P<0.001). The combined analysis for the recessive model also showed an increased risk of GC development for the GG genotype (OR, 1.65; 95\% CI, 1.45-1.87; $\mathrm{P}<0.001$ ). 


\section{Discussion}

Dysregulated $M D M 2$ expression has been shown to associated with several types of cancer due to its p53 regulatory functions (9). Under increased exposure to stress, p53 expression increases promoting transcriptional activity that leads to cell cycle arrest, repair and/or apoptosis (11). This increased p53 expression leads to increased mdm 2 protein expression since the MDM2 P2 promoter is p53-dependent, establishing an autoregulatory feedback loop (19). Indeed, $M D M 2$ is considered an oncogene because of its p53 inhibition function (19). Under physiological conditions, mdm2 E3 ubiquitin ligase domain binds the p53 transactivation domain, leading to the inhibition of the transcriptional activity of p53, followed by an increase in proteasomal degradation and ended by the export of p53 from the cell nucleus, which is crucial for the repression of p53 suppressor function (11). In addition to p53 regulation, MDM2 also serves an oncogenic function by interfering with the functions of other proteins that participate in several pathways, including DNA repair, apoptosis, motility and invasion (19). Studies have shown that $M D M 2$ amplification has been detected in several types of cancer, including GC $(10,19)$. In GC, MDM2 has been shown to be amplified (12) and overexpressed in GC tissues $(36,37)$, and this has also been associated with a higher grade of tumor differentiation, deeper invasion and nodal and distant metastasis (37).

Previous studies have shown an association between MDM2 and GC $(7,12)$. Considering the impact that some genetic polymorphisms have on the risk of developing GC, a systematic review was performed to clarify the associations between $M D M 2$ polymorphisms and GC. The NCBI SNP database contains a total of 9,642 MDM2 polymorphisms; however, only a few have been studied for their potential functional role in cancer. In the present study, only three different MDM2 polymorphisms (rs937283, rs3730485 and rs2279744) that have been studied in association with GC development were found. The previous studies on the rs2279744 and rs937283 polymorphisms suggested that they may affect expression of $M D M 2$, leading to higher degradation of $\mathrm{p} 53$ and consequently to the loss of the primary tumor suppressor pathways and therefore increase the risk of developing cancer.

The rs937283 polymorphism is characterized by an A to G change in the nucleotide at position 2,164 of the MDM2 promoter region, and this seems to lead to an increase in mdm2 expression $(26,38)$. This SNP was studied by Chen et al (26), and they concluded that it significantly increased the risk of developing GC in the Chinese population. In their study, the $\mathrm{G}$ allele was associated with an increased risk of developing GC either when $\mathrm{G}$ carriers vs. AA (OR, 1.34; P=0.024), and despite not being statistically significant, an association was observed for GG vs. A carriers (OR, 1.87; $\mathrm{P}=0.061)$. This SNP has been described to significantly enhance the transcriptional activity of the $M D M 2$ gene increasing the mRNA and protein levels, and additionally, this polymorphism has been studied in other types of cancer, such as lung cancer (26), liver cancer (39) and retinoblastoma (40), with similar effects reported.

The rs3730485 polymorphism, a 40 bp deletion in the P1 promoter of $M D M 2$, was studied by Cavalcante et al (27) in a Brazilian population, where it was shown to exert a protective effect against the development of GC, and is associated with an homozygous insertion of 40-bp (OR, 0.41; $\mathrm{P}=0.021)$. It has been suggested that the insertion of this 40-bp insert may reduce the activity of MDM2 and increase the availability of p53 in the cells reducing the chances of developing cancer. This polymorphism has been differentially associated with several types of cancer, including breast $(41,42)$, prostate $(42)$, ovarian (43) and hepatocellular carcinoma (44). Furthermore, it has been suggested that this SNP is in linkage disequilibrium with SNP 309, and therefore its impact may also be dependent on the SNP 309 genotype $(18,43)$.

The rs2279744, also known as SNP 309, is the most studied $M D M 2$ polymorphism and it is characterized by a $\mathrm{T}$ to $\mathrm{G}$ change in the nucleotide at position 309 of the $\mathrm{P} 2$ promoter of $M D M 2$. This genotype change seems to increase the affinity of the SP1 transcription factor, thus increasing mdm2 expression, and subsequently leading to increased inhibition of p53-dependent pathways (45). This polymorphism has been associated with several types of cancer, such as bladder (46), endometrial (47), cervical (48), hepatocellular (44) and colorectal cancer $(14,49)$, amongst other types of cancer. The literature review identified a total of 9 individual relevant case-controlled studies on the MDM2 rs2279744 polymorphism and GC risk. Of note, all studies were performed in Asian populations, most of them Chinese, which is expected, taking into account that these populations have the highest incidence rates of GC (50). Of the studies, 4 were not consistent with HWE $(23,28,29,31)$ and the funnel plots revealed that some of these studies may have bias that may be affecting their results. Nevertheless, the analysis revealed a significant association between the SNP $309 \mathrm{G}$ allele and increased risk of GC development, particularly in the homozygous model, in accordance with published studies $(23,28,30-32,34)$. Of the previously published meta-analyses regarding MDM2 SNPs and GC, all of them focused on SNP 309, 4 of which (with a range of 5-11 included manuscripts) showed that the SNP 309 $\mathrm{G}$ allele is associated with an increased risk of GC (51-54); 1 meta-analysis (which included 6 studies), showed the opposite association, but only the recessive model was analyzed (55); and the remaining 2 meta-analyses were not specific to GC; nevertheless they show an association between SNP 309 and cancer, overall $(45,56)$.

The present study has some limitations. First, regarding the genotyping methods, 1 study was performed using quantitative PCR (31), whereas the other five were performed using PCR-Restriction Fragment Length Polymorphism $(23,28,30,32,34)$. The different methods of genotyping may impact the quality of the genotyped data, since the specificity and sensitivity are variable and therefore, some variation in the genotype distribution is possible. Another source of limitations is the fact that the majority of studies are from the Chinese population, and the outcomes may not be applicable to individuals of other ethnicities. Nevertheless, China has a higher incidence of GC, which may explain the extra interest for studies of this nature, and may help to predict the potential impact in other areas at high-risk of GC (1). The low number of studies, some of which had a smaller number of cases may also impact the quality of the data analyzed. Indeed, qualitative analysis of studies should be performed once there is more significant data. Another issue is the importance of considering the role of $\mathrm{mdm} 2$ in the molecular mechanisms 
underlying gastric carcinogenesis, and the lack of information regarding its expression in precursor lesions.

Numerous studies have shown the roles of genetic polymorphisms of several genes in almost every aspect of cancer, with a potential impact on the clinical outcomes. Several MDM2 polymorphisms have been studied, and some of these appear to affect protein expression, and therefore $M D M 2$ variants may have an impact on the treatment response when treated with MDM2 inhibitors, particularly in cases of cancer with a low frequency of p53 mutations (57-59). The present study revealed that three different MDM2 genetic polymorphisms (rs937282, rs3730485 and rs2279744) have been studied for their association with the development of GC. The present study showed that these three MDM2 polymorphisms were associated with GC development, particularly rs2279744 (SNP 309), which was significantly associated with GC development. The fact that the number of studies is low and the studied populations are primarily Asian emphasizes the need for more studies in other populations to corroborate the association of these polymorphisms with GC.

\section{Acknowledgements}

Not applicable.

\section{Funding}

This study was supported by the Northern Portugal Regional Operational Programme (NORTE 2020), under the Portugal 2020 Partnership Agreement, through the European Regional Development Fund (grant no. NORTE-01-0145-F EDER-000027).

\section{Availability of data and materials}

The datasets used and/or analyzed during the present study are available from the corresponding author on reasonable request.

\section{Authors' contributions}

MT obtained, analyzed and interpreted the data, and drafted the article. AT acquired the data and drafted the article. SC and $\mathrm{CC}$ contributed to the writing of the article and performed the final review of the contents. RM conceived and designed the study. HS conceived and designed the study, analyzed and interpreted the data, and revised the manuscript. HS and MT confirm the authenticity of all the raw data. All authors have read and approved the final manuscript.

\section{Ethics approval and consent to participate}

Not applicable.

\section{Patient consent for publication}

Not applicable.

\section{Competing interests}

The authors declare that they have no competing interests.

\section{References}

1. Bray F, Ferlay J, Soerjomataram I, Siegel RL, Torre LA and Jemal A: Global cancer statistics 2018: GLOBOCAN estimates of incidence and mortality worldwide for 36 cancers in 185 countries. CA Cancer J Clin 68: 394-424, 2018.

2. Röcken C: Molecular classification of gastric cancer. Expert Rev Mol Diagn 17: 293-301, 2017.

3. Correa P: A human model of gastric carcinogenesis. Cancer Res 48: 3554-3560, 1988.

4. Amieva M and Peek RM Jr: Pathobiology of Helicobacter pylori-Induced Gastric Cancer. Gastroenterology 150: 64-78, 2016.

5. Cavatorta O, Scida S, Miraglia C, Barchi A, Nouvenne A, Leandro G, Meschi T, De' Angelis GL and Di Mario F: Epidemiology of gastric cancer and risk factors. Acta Biomed 89: 82-87, 2018.

6. Melchiades JL, Zabaglia LM, Sallas ML, Orcini WA, Chen E, Smith MAC, Payão SLM and Rasmussen LT: Polymorphisms and haplotypes of the interleukin 2 gene are associated with an increased risk of gastric cancer. The possible involvement of Helicobacter pylori. Cytokine 96: 203-207, 2017.

7. Busuttil RA, Zapparoli GV, Haupt S, Fennell C, Wong SQ, Pang JM, Takeno EA, Mitchell C, Di Costanzo N, Fox S, et al: Role of p53 in the progression of gastric cancer. Oncotarget 5: 12016-12026, 2014.

8. Aubrey BJ, Strasser A and Kelly GL: Tumor-suppressor functions of the TP53 pathway. Cold Spring Harb Perspect Med 6: a026062, 2016.

9. Yu H, Huang YJ, Liu Z, Wang LE, Li G, Sturgis EM, Johnson DG and Wei Q: Effects of MDM2 promoter polymorphisms and p53 codon 72 polymorphism on risk and age at onset of squamous cell carcinoma of the head and neck. Mol Carcinog 50: 697-706, 2011.

10. Baliou E, Nonni A, Keramopoulos D, Ragos V, Tsiambas E, Patsouris E and Pavlakis K: Deregulation of p53-MDM2 auto-regulatory pathway in breast carcinoma. J BUON 21: 1099-1103, 2016

11. Bond GL, Hu W and Levine AJ: MDM2 is a central node in the p53 pathway: 12 years and counting. Curr Cancer Drug Targets 5: 3-8, 2005.

12. Günther T, Schneider-Stock R, Häckel C, Kasper HU, Pross M, Hackelsberger A, Lippert H and Roessner A: Mdm2 gene amplification in gastric cancer correlation with expression of Mdm2 protein and p53 alterations. Mod Pathol 13: 621-626, 2000.

13. Ooi A, Oyama T, Nakamura R, Tajiri R, Ikeda H, Fushida S, Nakamura $\mathrm{H}$ and Dobashi Y: Semi-comprehensive analysis of gene amplification in gastric cancers using multiplex ligation-dependent probe amplification and fluorescence in situ hybridization. Mod Pathol 28: 861-871, 2015.

14. Qin X, Peng Q, Tang W, Lao X, Chen Z, Lai H, Deng Y, Mo C, Sui $\mathrm{J}, \mathrm{Wu} \mathrm{J}$, et al: An updated meta-analysis on the association of MDM2 SNP309 polymorphism with colorectal cancer risk. PLoS One 8: e76031,2013.

15. Sousa H, Pando M, Breda E, Catarino R and Medeiros R: Role of the MDM2 SNP309 polymorphism in the initiation and early age of onset of nasopharyngeal carcinoma. Mol Carcinog 50: 73-79, 2011.

16. Varmazyar S, Marashi SM, Shoja Z, Tornesello ML, Buonaguro FM, Shahmahmoodi S, Safaie-Naraghi Z and Jalilvand S: MDM2 gene polymorphisms and risk of classic Kaposi's sarcoma among Iranian patients. Med Microbiol Immunol (Berl) 206: 157-163, 2017.

17. Grochola LF, Zeron-Medina J, Mériaux S and Bond GL: Single-nucleotide polymorphisms in the p53 signaling pathway. Cold Spring Harb Perspect Biol 2: a001032, 2010.

18. Gansmo LB, Vatten L, Romundstad P, Hveem K, Ryan BM, Harris CC, Knappskog S and Lønning PE: Associations between the MDM2 promoter P1 polymorphism del1518 (rs3730485) and incidence of cancer of the breast, lung, colon and prostate. Oncotarget 7: 28637-28646, 2016.

19. Nag S, Qin J, Srivenugopal KS, Wang M and Zhang R: The MDM2-p53 pathway revisited. J Biomed Res 27: 254-271, 2013.

20. Mendoza M, Mandani G and Momand J: The MDM2 gene family. Biomol Concepts 5: 9-19, 2014.

21. Elingarami S, Liu H, Kalinjuma AV, Hu W, Li S and He N: Polymorphisms in NEIL-2, APE-1, CYP2E1 and MDM2 genes are independent predictors of gastric cancer risk in a Northern Jiangsu population (China). J Nanosci Nanotechnol 15: 4815-4828, 2015 . 
22. Moradi MT, Salehi Z, Aminian K and Yazdanbod A: Effects of p53 codon 72 and MDM2 SNP309 polymorphisms on gastric cancer risk among the Iranian population. Asian Pac J Cancer Prev 15: 7413-7417, 2014

23. Ohmiya N, Taguchi A, Mabuchi N, Itoh A, Hirooka Y, Niwa Y and Goto H: MDM2 promoter polymorphism is associated with both an increased susceptibility to gastric carcinoma and poor prognosis. J Clin Oncol 24: 4434-4440, 2006.

24. Page MJ, Moher D, Bossuyt PM, Boutron I, Hoffmann TC, Mulrow CD, Shamseer L, Tetzlaff JM, Akl EA, Brennan SE, et al: PRISMA 2020 explanation and elaboration: Updated guidance and exemplars for reporting systematic reviews. BMJ 372: n160, 2021.

25. Wells GA, Shea B, O'Connell D, Peterson J, Welch V, Losos M and Tugwell P: The Newcastle-Ottawa Scale (NOS) for Assessing the Quality of Nonrandomised Studies in Meta-Analyses. Ottawa Health Research Institute, Ottawa, Ontario, 1999.

26. Chen B, Wang J, Chen Y, Gu X and Feng X: The MDM2 rs937283 $\mathrm{A}>\mathrm{G}$ variant significantly increases the risk of lung and gastric cancer in Chinese population. Int J Clin Oncol 23: 867-876, 2018

27. Cavalcante GC, Amador MA, Ribeiro Dos Santos AM, Carvalho DC, Andrade RB, Pereira EE, Fernandes MR, Costa DF, Santos NP, Assumpção PP, et al: Analysis of 12 variants in the development of gastric and colorectal cancers. World J Gastroenterol 23: 8533-8543, 2017.

28. Tas A, Atabey M, Caglayan G, Bostanci ME, Sahin Bolukbasi S, Topcu $\mathrm{O}$ and Silig Y: Investigation of the association between the MDM2 T309G polymorphism and gastric cancer. Biomed Rep 7: 469-473, 2017.

29. Moradi MT, Salehi Z, Asl SF, Aminian K and Hashtchin AR: Helicobacter pylori infection and MDM2 SNP309 association with gastric cancer susceptibility. Genet Test Mol Biomarkers 17: 794-798, 2013

30. Pan X, Li Y, Feng J, Wang X, Hao B, Shi R and Zhang G: A functional polymorphism T309G in MDM2 gene promoter, intensified by Helicobacter pylori lipopolysaccharide, is associated with both an increased susceptibility and poor prognosis of gastric carcinoma in Chinese patients. BMC Cancer 13: 126, 2013.

31. Wu GC and Zhang ZT: Genetic association of single nucleotide polymorphisms in P53 pathway with gastric cancer risk in a Chinese Han population. Med Oncol 32: 401, 2015.

32. Wang X, Yang J, Ho B, Yang Y, Huang Z, Zhang Z and Zhang G: Interaction of Helicobacter pylori with genetic variants in the MDM2 promoter, is associated with gastric cancer susceptibility in Chinese patients. Helicobacter 14: 114-119, 2009.

33. Cho YG, Choi BJ, Song JH, Kim CJ, Cao Z, Nam SW, Lee JY and Park WS: No association of MDM2 T309G polymorphism with susceptibility to Korean gastric cancer patients. Neoplasma 55: 256-260, 2008

34. Yang M, Guo Y, Zhang X, Miao X, Tan W, Sun T, Zhao D, Yu D, Liu J and Lin D: Interaction of P53 Arg72Pro and MDM2 T309G polymorphisms and their associations with risk of gastric cardia cancer. Carcinogenesis 28: 1996-2001, 2007.

35. Horita N and Kaneko T: Genetic model selection for a case-control study and a meta-analysis. Meta Gene 5: 1-8, 2015.

36. Kasper HU, Schneider-Stock R, Mellin W, Günther T and Roessner A: P53-protein accumulation and MDM2-protein overexpression in gastric carcinomas. No apparent correlation with survival. Pathol Res Pract 195: 815-820, 1999.

37. Aboushousha T, Helal N, Hammam O, Ibrahim M, Khaled S, Mostafa A and Anas A: Overview of MDM2 and B-RAF Expression in Gastric Lesions. Open Access Maced J Med Sci 6: 1795-1802, 2018

38. Jiao Y, Jiang Z, Wu Y, Chen X, Xiao X and Yu H: A Functional Polymorphism (rs937283) in the MDM2 Promoter Region is Associated with Poor Prognosis of Retinoblastoma in Chinese Han Population. Sci Rep 6: 31240, 2016.

39. Chen B, Wang J, Wang J, Zhang J, Gu X and Feng X: The Study of MDM2 rs937283 Variant and Cancer Susceptibility in a Central Chinese Population. Technol Cancer Res Treat 17: 1533033818801550,2018

40. Cao Q, Wang Y, Song X and Yang W: Association between MDM2 rs2279744, MDM2 rs937283, and p21 rs1801270 polymorphisms and retinoblastoma susceptibility. Medicine (Baltimore) 97: e13547, 2018.
41. Gallegos-Arreola MP, Márquez-Rosales MG, Sánchez-Corona J, Figuera LE, Zúñiga-González G, Puebla-Pérez AM, Delgado-Saucedo JI and Montoya-Fuentes H: Association of the Del1518 Promoter (rs3730485) Polymorphism in the MDM2 Gene with Breast Cancer in a Mexican Population. Ann Clin Lab Sci 47: 291-297, 2017.

42. Hashemi M, Amininia S, Ebrahimi M, Simforoosh N, Basiri A, Ziaee SAM, Narouie B, Sotoudeh M, Mollakouchekian MJ, Rezghi Maleki E, et al: Association between polymorphisms in TP53 and MDM2 genes and susceptibility to prostate cancer. Oncol Lett 13: 2483-2489, 2017.

43. Gansmo LB, Bjørnslett M, Halle MK, Salvesen HB, Romundstad P, Hveem K, Vatten L, Dørum A, Lønning PE and Knappskog S: MDM2 promoter polymorphism del1518 (rs3730485) and its impact on endometrial and ovarian cancer risk. BMC Cancer 17: 97, 2017.

44. Dong D, Gao X, Zhu Z, Yu Q, Bian S and Gao Y: A 40-bp insertion/deletion polymorphism in the constitutive promoter of MDM2 confers risk for hepatocellular carcinoma in a Chinese population. Gene 497: 66-70, 2012.

45. Wan Y, Wu W, Yin Z, Guan P and Zhou B: MDM2 SNP309, gene-gene interaction, and tumor susceptibility: An updated meta-analysis. BMC Cancer 11: 208, 2011.

46. Avirmed S, Wang BS, Selenge B, Sanjaajamts A, Ganbat B, Erdenebileg U, Purevsuren M, Jigjidsuren S, Batmunkh $M$ and Lee YJ: Association between MDM2-SNP309 and p53R72P polymorphisms and the risk of bladder cancer in the Mongolian population. Mol Clin Oncol 7: 412-420, 2017.

47. Zou X, Zhang Y, Zhang L, Li J, Zhu C, Cheng Q, Zhou J and Chen Y: Association between MDM2 SNP309 and endometrial cancer risk: A PRISMA-compliant meta-analysis. Medicine (Baltimore) 97: e13273, 2018.

48. Knappskog S and Lønning PE: MDM2 SNP309 and risk of cervical cancer. Tumour Biol 35: 6185-6186, 2014.

49. Wang W, Du M, Gu D, Zhu L, Chu H, Tong N, Zhang Z, Xu Z and Wang M: MDM2 SNP309 polymorphism is associated with colorectal cancer risk. Sci Rep 4: 4851, 2014.

50. Sung H, Ferlay J, Siegel RL, Laversanne M, Soerjomataram I, Jemal A and Bray F: Global cancer statistics 2020: GLOBOCAN estimates of incidence and mortality worldwide for 36 cancers in 185 countries. CA Cancer J Clin 71: 209-249, 2021.

51. Shen W, Hu P, Cao JQ, Liu XX and Shao JH: MDM2 oncogene, E3 ubiquitin protein ligase T309G polymorphism and risk of oesophageal or gastric cancer: Meta-analysis of 15 studies. J Int Med Res 42: 1065-1076, 2014.

52. Chen W, Wu Q and Ren H: Meta-analysis of associations between MDM2 SNP309 polymorphism and gastric cancer risk. Biomed Rep 2: 105-111, 2014.

53. Song B, Duan ZY, Zhong YH, Lei N, Yang YQ and Luo KY: Meta-analysis of the MDM2 T309G polymorphism and gastric cancer risk. Asian Pac J Cancer Prev 14: 6649-6651, 2014.

54. Ma Y, Bian J and Cao H: MDM2 SNP309 rs2279744 polymorphism and gastric cancer risk: A meta-analysis. PLoS One 8: e56918, 2013.

55. Tian X, Tian Y, Ma P, Sui CG, Meng FD, Li Y, Fu LY, Jiang T, Wang Y, Ji FJ, et al: Association between MDM2 SNP309 T>G and risk of gastric cancer: A meta-analysis. Asian Pac J Cancer Prev 14: 1925-1929, 2013.

56. Chen B, Cao L, Hu KW, Zhang JW, Meng XL and Xiong MM: MDM2 SNP309 is an ethnicity-dependent risk factor for digestive tract cancers. Tumour Biol 35: 3431-3438, 2014.

57. Ohnstad HO, Castro R, Sun J, Heintz KM, Vassilev LT, Bjerkehagen B, Kresse SH, Meza-Zepeda LA and Myklebost O: Correlation of TP53 and MDM2 genotypes with response to therapy in sarcoma. Cancer 119: 1013-1022, 2013.

58. Tisato V, Voltan R, Gonelli A, Secchiero P and Zauli G: MDM2/X inhibitors under clinical evaluation: Perspectives for the management of hematological malignancies and pediatric cancer. J Hematol Oncol 10: 133, 2017.

59. Gupta A, Shah K, Oza MJ and Behl T: Reactivation of p53 gene by MDM2 inhibitors: A novel therapy for cancer treatment. Biomed Pharmacother 109: 484-492, 2019. 